Revista Brasileira de Cartografia

ISSN 1808-0936 | https://doi.org/10.14393/revbrascartogr

Sociedade Brasileira de Cartografia, Geodésia, Fotogrametria e Sensoriamento Remoto

\title{
Controle Geodésico do Nível do Mar em Salvador: Análises e Correlações
}

\section{Geodetic Sea Level Control in Salvador: Analysis and Correlations}

\author{
Nilton de Souza Ribas Junior ${ }^{1}$, Carlos Antônio de Souza Teles Santos ${ }^{2}$, Gilney Figueira Zebende ${ }^{3}$ e Aloísio Machado \\ da Silva Filho 4
}

1 Universidade Estadual de Feira de Santana, Programa de Pós-graduação em Modelagem em Ciências da Terra e do Ambiente, Feira de Santana, Brasil. niltonribasjr@gmail.com.

ORCID: https://orcid.org/0000-0003-2170-136X

2 Universidade Estadual de Feira de Santana, Programa de Pós-graduação em Modelagem em Ciências da Terra e do Ambiente, Feira de Santana, Brasil. carlossateles@yahoo.com.br.

ORCID: https://orcid.org/0000-0003-0970-0479

3 Universidade Estadual de Feira de Santana, Programa de Pós-graduação em Modelagem em Ciências da Terra e do Ambiente, Feira de Santana, Brasil.gfzebende@uefs.br.

ORCID: https://orcid.org/0000-0003-2420-9805

4 Universidade Estadual de Feira de Santana, Programa de Pós-graduação em Modelagem em Ciências da Terra e do Ambiente, Feira de Santana, Brasil. aloisioestatistico@uefs.br.

ORCID: https://orcid.org/0000-0001-8250-1527

Resumo: Fatores de ordem política, social e econômica têm motivado governantes e pesquisadores a monitorar e estudar o comportamento do nível do mar. Com a elevação deste nível, estima-se que em 2070150 milhões de pessoas estariam em risco e uma riqueza avaliada em 35 trilhões de dólares ameaçados nas 136 maiores cidades portuárias do mundo. Para a engenharia, o nível médio do mar tem fundamental importância na determinação do datum altimétrico de um país. Neste trabalho foram utilizados os dados coletados pela Estação Maregráfica de Salvador no período de 2009 a 2015 com o objetivo de avaliar o comportamento temporal do nível médio do mar neste local, detectar e quantificar movimentos verticais de origem não oceânica que tendem a degradar e mascarar a qualidade desses dados. Rotinas computacionais foram desenvolvidas no intuito de detectar e corrigir inconsistências nesta série. Métodos estatísticos de regressão, além do DFA e $\rho$ DCCA foram utilizados para analisar o comportamento da série, sua persistência ao longo do tempo e quantificar o nível de correlação cruzada entre a série maregráfica e as redes geodésicas ativas e passivas do IBGE. Os resultados mostraram a importância na análise e correção dos dados para fins de determinação do nível médio do mar por apresentar diferenças numéricas, mas qualitativamente não houve diferença significativa, visto o universo de pontos analisados. Nossos achados apontam que o nível do mar está subindo e, além disso, este cenário tende a continuar por um longo período.

Palavras-chave: Estação Maregráfica. Nível Médio do Mar. Sistema GNSS. Análise de Séries Temporais.

\begin{abstract}
Political, social and economic factors have motivated government officials and researchers to monitor and study the behavior of sea levels. With the rise of this level, it is estimated that in 2070150 million people would be at risk and a wealth estimated at 35 trillion dollars threatened in the 136 largest port cities in the world. For engineering, the mean sea level is of fundamental importance in determining a country's altimetric datum. In this work were used the data collected by the Salvador Tide Gauge in the period from 2009 to 2015 with the objective not only of evaluating the temporal behavior of the mean sea level in this place, in addition to detecting and quantifying vertical movements of non-oceanic origin that tend to degrade and mask the quality of these data. Computational routines were developed in order to detect and correct inconsistencies in this series. Statistical regression methods, in addition to DFA and $\rho \mathrm{DCCA}$, were used to analyze the series' behavior, its persistence over time and to quantify the level of crosscorrelation between the tidal gauge series and the IBGE active and passive geodesic networks. The results showed the importance in the analysis and correction of the tide gauge series for the purpose of determining the mean sea level by presenting numerical differences, but qualitatively there was no significant difference, given the universe of points analyzed. Our findings indicate that the sea level is rising and, moreover, this scenario tends to continue for a long time.
\end{abstract}

Keywords: Tide Gauge Station. Mean See Level. GNSS System. Time Series Analysis. 


\section{INTRODUÇÃO}

Há um certo tempo que os governantes e a comunidade científica têm se preocupado com o nível dos mares. Publicação de setembro de 2013 da revista National Geographics (FOLGER, 2013), baseado no relatório da OECD (2008) sobre as 136 maiores cidades portuárias do mundo, afirma que com o planeta mais quente, a elevação do nível dos oceanos se acentua, onde estima-se que em 2070150 milhões de pessoas nestas cidades estariam em risco e uma riqueza avaliada em 35 trilhões de dólares ameaçados. Esse aumento do nível do mar se daria principalmente pelo consumo de combustíveis fósseis pela sociedade que ao liberar na atmosfera dióxido de carbono e outros gases do efeito estufa, aqueceram a Terra em mais de meio grau celsius ao longo do século passado, complementa a publicação.

De fato, o quinto relatório apresentado pelo IPCC (Intergovernmental Panel on Climate Change), mostra que a expansão térmica dos oceanos e o derretimento de geleiras têm sido os contribuintes dominantes para o aumento do nível médio do mar global do século 20. Observações desde 1971 indicam que esse aumento do nível médio do mar global vai continuar para além de 2100 (IPCC, 2013).

Para o IBGE (Instituto Brasileiro de Geografia e Estatística), gestor do Sistema Geodésico Brasileiro (SGB), o nível do mar tem fundamental importância na determinação do datum altimétrico oficial do país.

Embora estudos recentes venham sendo desenvolvidos para modelagem do nível médio do mar global (TOCHO et al., 2020; CORDEIRO, 2019; SANCHEZ e SIDERIS, 2017; IHDE et al., 2017), após publicação do IAG (Internacional Association of Geodesy) para definição e realização de um sistema internacional de referência altimétrico (IHRS) que visa principalmente a integração de altitudes entre países (IAG, 2015), a presente pesquisa tem seu foco em modelos de estações usualmente encontradas para fins de determinação do nível médio do mar. No Brasil, existem atualmente seis estações maregráficas ativas controladas pelo IBGE e distribuídas ao longo da costa, sendo elas: Imbituba-SC, Arraial do Cabo-RJ, Salvador-BA, Fortaleza-CE, Belém-PA e Santana-AP.

Para que se tenha um registro maregráfico fornecido por essas estações de modo confiável, é preciso detectar, quantificar e isolar todo e qualquer movimento vertical que possa interferir nesses dados, aqui chamados de movimentos verticais de origem não oceânica, tais como: movimentos da crosta terrestre, instabilidade nas estruturas de suporte dos sensores, etc., além dos erros originalmente instrumentais que são tão frequentes e que são extremamente necessários corrigi-los para tornarmos a série o mais fidedigna possível.

Vale ressaltar que todos esses erros são detectáveis e possíveis de serem modelados, classificados então como erros sistemáticos, podendo estes serem corrigidos a priori ou a posteriori, provenientes de fontes instrumentais ou de fontes ambientais. Entretanto, diante da grande quantidade de dados manipulados, foi fundamental a elaboração de rotinas computacionais, sugerindo soluções de desenvolvimento para atenuar esses efeitos de origem não oceânica, nas suas esferas de controle planimétrico, altimétrico e instrumental.

Métodos estatísticos de regressão linear foram utilizados para analisar o comportamento da série, assim como o DFA (Detrended Fluctuation Analysis) para avaliar sua memória ao longo do tempo, além da utilização do $\rho$ DCCA (coeficiente capaz de quantificar o nível de correlação cruzada, tendo como base o DFA e o DCCADetrended Cross-Correlation Analysis), correlacionando os dados da série maregráfica com outros dados advindos das redes geodésicas ativas e passivas do IBGE.

O tema é atual e relevante, visto as discussões a nível global com respeito ao assunto. Parra, Lopéz e Franco (2006), por exemplo, analisaram a variação do nível médio do mar no caribe colombiano, Neto (2009) estudou os impactos do aumento do nível médio do mar no nordeste brasileiro e suas consequências do ponto de vista ambiental, Santos et al. (2015) traçaram uma metodologia para mapeamento de vulnerabilidade costeira, enquanto que Albarici et al. (2019) modelaram os efeitos geodinâmicos que afetam as medições maregráficas e GNSS (Global Navigation Satellite System). Já Sampaio, Melo, Faria e Menezes (2003) fizeram uma análise temporal desde a época do período terciário das possíveis consequências do avanço do nível do mar para o Brasil, entre tantos outros. Mas apesar de ter sido pesquisado, não se verificou na literatura até o momento trabalhos de monitoramento do nível médio do mar com a utilização dos métodos estatísticos DFA e $\rho$ DCCA. São métodos relativamente novos e sua exploração se verifica mais no ramo da saúde e do mercado financeiro.

Para atender os objetivos desta pesquisa, este artigo está estruturado em 5 seções: introdução, métodos 
estatísticos empregados, materiais e métodos, resultados e discussões e por fim considerações finais.

\section{MÉTODOS ESTATÍSTICOS EMPREGADOS}

\subsection{Regressão Linear}

O principal objetivo deste modelo é obter uma equação que explique a relação linear entre uma variável resposta e uma ou mais variáveis explicativas, possibilitando fazer predição de valores da variável de interesse (GUIMARÃES, 2008). Ainda segundo o autor, a equação que descreve essa relação é dada por:

$$
Y=a+b X+\varepsilon
$$

Em que $\mathrm{X}$ e $\mathrm{Y}$ exercem uma relação linear determinística e o $\varepsilon$ quantifica o erro ou resíduo do modelo proposto.

Ainda para estimar os parâmetros do modelo é necessário um método de estimação que se ajuste a melhor equação possível aos dados observados, sendo o método dos mínimos quadrados o mais recomendado pela sua precisão, de modo que a soma dos quadrados dos resíduos seja mínima (GUIMARÃES, 2008).

$$
S Q=\sum_{i=1}^{n} \varepsilon_{i}^{2}=\sum_{i=1}^{n}\left(y_{i}-a-b X_{i}\right)
$$

Após algumas operações algébricas, os estimadores resultantes são:

$$
\begin{gathered}
b=\frac{\sum x_{i} y_{i}-n \overline{y x}}{\sum x_{i}^{2}-n \bar{x}^{2}} \\
a=\bar{y}-b \bar{x}
\end{gathered}
$$

Em que $\bar{y}$ é a média amostral dos $y_{i}$ e $\bar{x}$ a média amostral dos $x_{i}$. Logo, $\mathrm{E}(\mathrm{Y} \mid \mathrm{x})=\mathrm{a}+\mathrm{bX}$ é o modelo de regressão linear simples ajustado, em que $\mathrm{E}(\mathrm{Y} \mid \mathrm{x})$, denotado também por $\hat{Y}$, é o valor médio predito de $\mathrm{Y}$ para qualquer valor $\mathrm{X}=\mathrm{x}$ que esteja na variação observada de $\mathrm{X}$.

Segundo Cordeiro e Paula (1989), esse método não necessariamente produzirá as mesmas estimativas que o método da máxima verossimilhança quando $\varepsilon$ não tiver distribuição normal. Neste caso, tal estimativa é obtida minimizando a soma dos erros absolutos em vez da soma dos quadrados dos erros.

\subsection{Detrended Fluctuation Analysis (DFA)}

O DFA (Detrended Fluctuation Analysis) foi idealizado por Peng et al. (1994) e pode ser aplicado para identificar e mensurar autocorrelação de longo alcance em séries temporais não estacionárias. Sua peculiaridade é permitir a identificação de auto-afinidade e identificação de correlações de longo alcance em séries temporais com tendências (SILVA FILHO, 2014). Sua modelagem se dá com os seguintes passos (SILVA FILHO, 2014; MACHADO FILHO; SILVA; ZEBENDE, 2014):

Passo 1 - Calcula-se o desvio padrão de cada registro em relação à incidência média da série completa, integrando o sinal $u_{i}$ (série original) e obtendo-se a série integrada $y(k)$ pela seguinte expressão:

$$
y(k)=\sum_{i-1}^{k}\left(u_{i}-\langle u\rangle\right) ; \quad k=1,2 \ldots N
$$

em que $\langle u\rangle$ denota o valor médio de $u_{i}$, e $N$, o total de pontos da série.

Passo 2 - Em seguida a série integrada $y(k)$ é dividida em intervalos de igual tamanho $n$ não sobrepostos. E para cada intervalo de tamanho $n$, é preciso ajustar um polinômio de grau maior ou igual a 1 
a $y(k)$, denotado por $y_{n}(k)$. Essa estatística representa a tendência local na amplitude de tamanho $n$.

Passo 3 - Logo após, a série integrada $y(k)$, é subtraída de $y_{n}(k)$ em cada intervalo de tamanho $n$, com base na seguinte expressão:

$$
F_{D F A}(n)=\sqrt{\frac{1}{N} \sum_{k=1}^{N}\left[y(k)-y_{n}(k)\right]^{2}}
$$

e o cálculo anterior é repetido sistematicamente para diferentes amplitudes de tamanho $n$ variando de $\left(4 \leq n \leq \frac{N}{4}\right)$.

Passo 4 - Verificar se $F_{D F A}(n)$ tem comportamento de acordo com a Eq. (7)

$$
F_{D F A}(n) \approx n^{\alpha}
$$

Neste caso, $\alpha$ representa o expoente de correlação de longo alcance.

$$
F_{D F A}(n)=a n^{\alpha}
$$

Aplicando log na Eq. (8), tem-se:

$$
\log F_{D F A}(n)=\log a+\alpha \log n
$$

Através do expoente $\alpha$ obtido por meio do DFA é possível avaliar em que medida a tendência observada na série temporal passada implica em manutenção do comportamento no futuro, indicando um efeito de memória de longa duração na série (SILVA FILHO, 2014). No caso de séries temporais não correlacionadas, espera-se $\alpha=0,50$, caso comum em séries sem memória. Se $\alpha>0,50$, pode-se inferir que a série apresenta comportamento persistente de longo alcance. Caso $\alpha<0,50$, espera-se um comportamento antipersistente, complementa o autor.

\subsection{Detrended Cross-Correlation Analysis (DCCA)}

O DCCA (Detrended Cross-Correlation Analysis) é uma generalização do método DFA, utilizado para identificar correlação cruzada entre duas séries temporais em regime não estacionário com o mesmo número de observações de tamanho $N$. Sua modelagem se dá com os seguintes passos (PODOBNIK; STANLEY, 2008):

Passo 1 - Integram-se duas séries $\left\{y_{i}\right\}$ e $\left\{y_{i}^{\prime}\right\}$ por meio das seguintes expressões:

$$
\begin{aligned}
& R_{k}=y_{1}+y_{2}+y_{3}+\cdots+y_{k} \\
& R_{k}^{\prime}=y_{1}^{\prime}+y_{2}^{\prime}+y_{3}^{\prime}+\cdots+y_{k}^{\prime}
\end{aligned}
$$

Em que $K=1,2, \ldots, N$

Passo 2 - Divide-se os sinais integrados $R_{k}$ e $R_{k}^{\prime}$ em $(N-n)$ boxes (com superposição) de tamanho $n$, cada um contendo $n+1$ valores. Para as duas séries temporais, em cada box (que inicia em $i$ e termina em $i+n)$, calcula-se as tendências em cada box, isto é, $\tilde{R}_{k, i}$ e $\tilde{R}_{k, i}^{\prime}$ como sendo a ordenada do ajuste linear (processo dos mínimos quadrados) da série somada.

Passo 3 - A partir dos resultados obtidos pelas Eq. (10) e Eq. (11), calcula-se a covariância dos resíduos em cada intervalo, ou seja, 


$$
f_{D C C A}^{2}(n, i)=\frac{1}{(n+1)} \sum_{K=1}^{i+n}\left(R_{k}-\tilde{R}_{k, i}\right)\left(R_{k}^{\prime}-\tilde{R}_{k, i}^{\prime}\right)
$$

Passo 4 - Calcula-se a função de correlação expressa como:

$$
F_{D C C A}^{2}(n) \equiv \frac{1}{N-n} \sum_{i=1}^{N-n} f_{D C C A}^{2}(n, i)
$$

Se o procedimento da Eq. (13) for repetido para diferentes tamanhos de $n$ sistematicamente, é possível constatar a existência ou não de uma lei de potência em que $\lambda$ quantifica a correlação cruzada, ou seja,

$$
F_{D C C A} \sim n^{\lambda}
$$

Já o pDCCA, modelado por Zebende (2011), é um coeficiente capaz de quantificar o nível de correlação cruzada, tendo como base o DFA e o DCCA, destinando-se a estimação do coeficiente de correlação cruzada em diferentes escalas de tamanho $n$, cujo coeficiente possui sua variação limitada entre $-1 \mathrm{e}+1$, em que -1 representa anticorrelação perfeita e +1 correlação perfeita. Define-se como a relação entre a função de covariância sem tendência $F_{D C C A}^{2}$ e a função de variância sem tendência $F_{D F A}$, conforme expresso abaixo:

$$
\rho D C C A(n) \cong \frac{F_{D C C A}^{2}(n)}{F_{D F A 1}(n) F_{D F A 2}(n)}
$$

Uma de suas vantagens é a possibilidade de mensurar a correlação entre as séries em escalas diferentes de tempo e sua análise é feita sem a componente tendência que tende a mascarar as verdadeiras correlações (ZEBENDE; SILVA; MACHADO FILHO, 2014).

\section{MATERIAIS E MÉTODOS}

\section{1 Área de Estudo}

A Baía de Todos os Santos, conhecida como BTS, está localizada nas bordas da cidade de SalvadorBA, sendo a segunda maior baía do Brasil e a única que apresenta terminais portuários de grande porte, um canal de entrada naturalmente navegável e canais internos profundos, o que, desde sempre, a tem tornado um elemento facilitador do desenvolvimento da região (HATJE; ANDRADE, 2009). É na parte sul da BTS, mais precisamente nas coordenadas $12^{\circ} 58^{\prime} 26^{\prime \prime}$ de latitude sul e $38^{\circ} 31^{\prime} 02^{\prime \prime}$ de longitude oeste, que se encontra o complexo de sensores da Estação Maregráfica de Salvador, também chamada de EMSAL (Figura 1). 
Figura 1 - Estação Maregráfica EMSAL e RBMC SSA1.

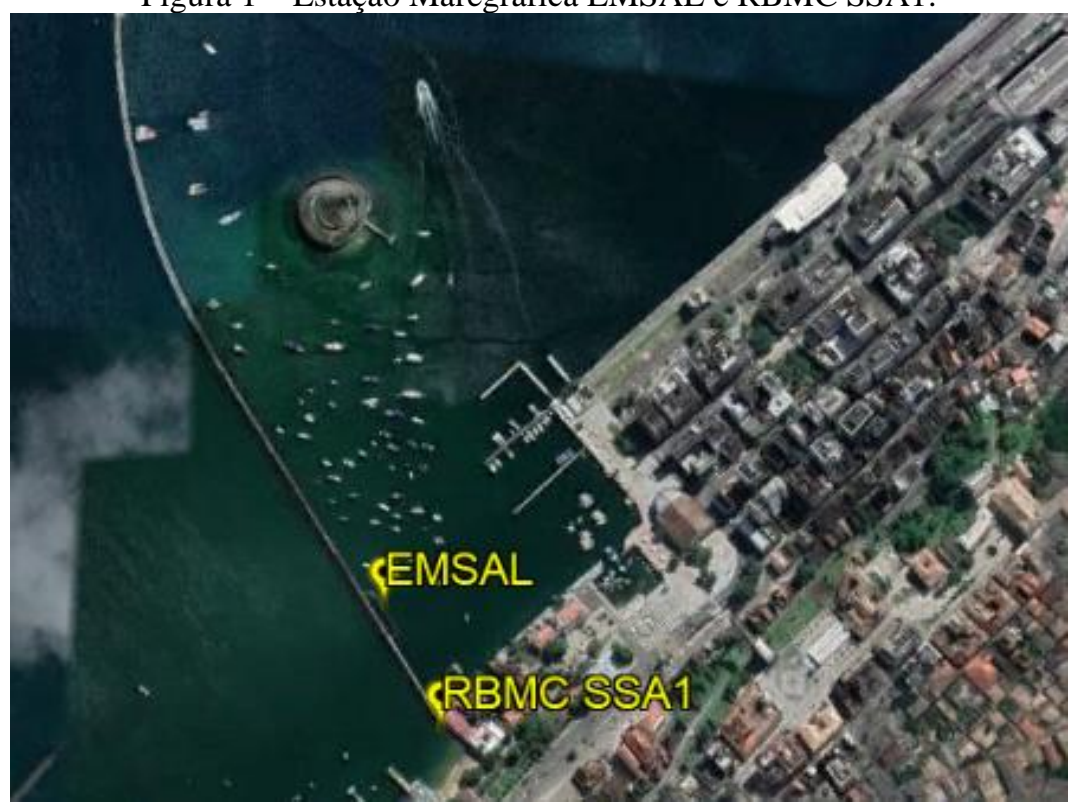

Fonte: Adaptada de Google Earth (2020).

\subsection{Fonte de Dados}

Para este estudo foram utilizados os dados da Estação Maregráfica de Salvador entre julho de 2009 a dezembro de 2015. De acordo com Marmer (1951), 19 anos de análise de dados representa o período mínimo ideal de observações para a obtenção dos data altimétricos, necessários para que sejam reduzidos os efeitos das variações periódicas provocadas pelas influências astronômicas. Por outro lado, o período escolhido de 6,5 anos se dá pelo fato dos avanços e modernizações metodológicas relacionadas as atividades de controle geodésico das estações maregráficas só terem acontecido a partir de 2009, o que permite uma comparação no controle temporal e de precisão da correlação entre diversas superfícies físicas e geométricas de referência altimétrica (IBGE, 2017). Contudo, a EMSAL iniciou seu monitoramento em dezembro de 2002 com equipamentos mecânicos e outubro de 2004 com equipamentos eletrônicos, sendo eles: sensores radar Vegapuls 62 e encoder Sutron SDR-1-1 (Figura 2) e um datalogger Sutron Satlink desde abril de 2008, tendo operado até esta data com um sensor ultrasônico Aquatrak (IBGE, 2013). Logo, o sensor de radar, principal fonte geradora da série estatística em questão, está presente ao longo de todo o período escolhido.

Segundo o fabricante, o sensor de radar Vegapuls 62 pode ser usado numa grande variedade de aplicações para medições contínuas do nível de líquidos (VEGA GRIESHABER KG, 2012). Ao contrário de um sensor analógico, o sensor de radar não observa o nível da água diretamente e sim o tempo de percurso de um sinal eletromagnético entre o sensor e o nível d'água com uma duração de aproximadamente 1ns que é convertido posteriormente pela unidade de controle em informações referentes ao nível d'água (IBGE, 2010).

Já o encoder é um sistema de boia e contrapeso que converte as informações angulares em altura de maré, sendo a principal fonte de correção para os dados inconsistentes do radar.

Para os casos de inconsistência ou ausência tanto nos dados do radar quanto do encoder, estes são complementados com dados previsivos do SLPR2 (Sea Level Processing Package), pacote de processamento desenvolvido e documento pelo Joint Archive for Sea Level, numa colaboração entre a University of Hawaii Sea Level Center e o US National Oceanographic Data Center e que fornece uma estimativa confiável de informações do nível do mar específicas do local. Não se chegou a quantificar, mas para o caso específico de Salvador as respostas do SLPR2 são bem satisfatórias e apresentam boa aproximação quando comparamos os gráficos correspondentes aos dados do SLPR2 sobrepondo-o ao mesmo período com o gráfico correspondente aos dados do radar. 
Figura 2 - Sensor Radar em Salvador e modelo Encoder Sutron.

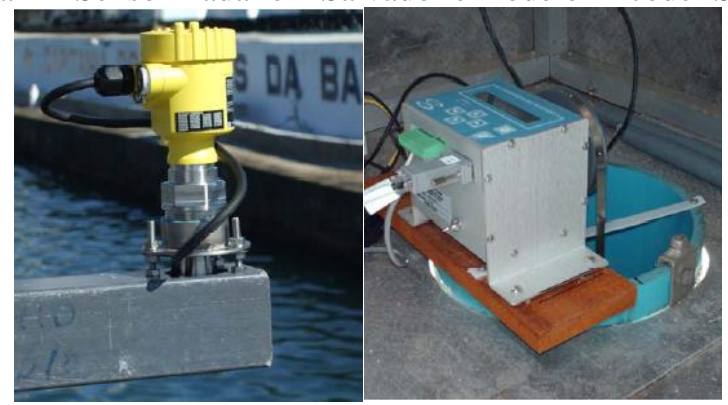

Fonte: IBGE (2010).

Outra série utilizada muito importante são os dados GNSS oriundos da RBMC SSA1 (Figura 3). Esta estação é dotada de antena e receptor de alta precisão e materializada por um pilar estável. Além disso, suas observações são processadas de acordo com procedimentos científicos, adequados ao monitoramento da posição tridimensional na ordem do milímetro. Desde sua implantação em maio de 2007 até outubro de 2012, a estação contava com um receptor da marca Trimble, modelo 4000SSI, enquanto que de 2012 até então a estação conta com um receptor mais moderno e mais preciso, modelo NetR8, também da marca Trimble, atendendo assim ao projeto da RBMC de permanente processo de modernização, buscando sempre tecnologias mais modernas, captando cada vez mais sistemas e consequentemente suas constelações.

Porém, a fim de eliminar os efeitos de carga oceânica no tratamento dos dados, foram utilizados os processamentos semanais da RBMC, denominado SIRGASCON (Rede SIRGAS de Monitoramento Contínuo), incorporado nas atividades do IBGE desde 2005 com o objetivo de avaliar a qualidade das observações e a manutenção do Sistema de Referência Geocêntrico SIRGAS2000. Vale ressaltar que durante o período em estudo, mais precisamente em abril de 2011, os processamentos GNSS passaram a estar referidos à nova realização do IGS (International GNSS Service), denominada IGS08. Consequentemente, a partir desta data, os processamentos GNSS que utilizam os produtos IGS terão seus resultados referidos a este novo sistema de referência, podendo acarretar descontinuidade nas coordenadas (COSTA et al., 2012).

Quanto ao processamento do SIRGASCON, este é feito no Bernese, software científico de processamento GNSS de alta precisão, desenvolvido pelo Astronomical Institute of the University of Bern e utilizado pelos principais centros de processamento GNSS no mundo. Não só isso, o Bernese permite no seu processamento a introdução dos dados de carga oceânica, assim como a modelagem de vários outros parâmetros que visam minimizar seus efeitos. Neste caso, o modelo de carga oceânica utilizado é o FES2014, última versão do modelo de maré FES (Finite Element Solution) e baseado na resolução das equações hidrodinâmicas de águas rasas (CARRÈRE et al., 2016).

Figura 3 - Estação da RBMC SSA1.

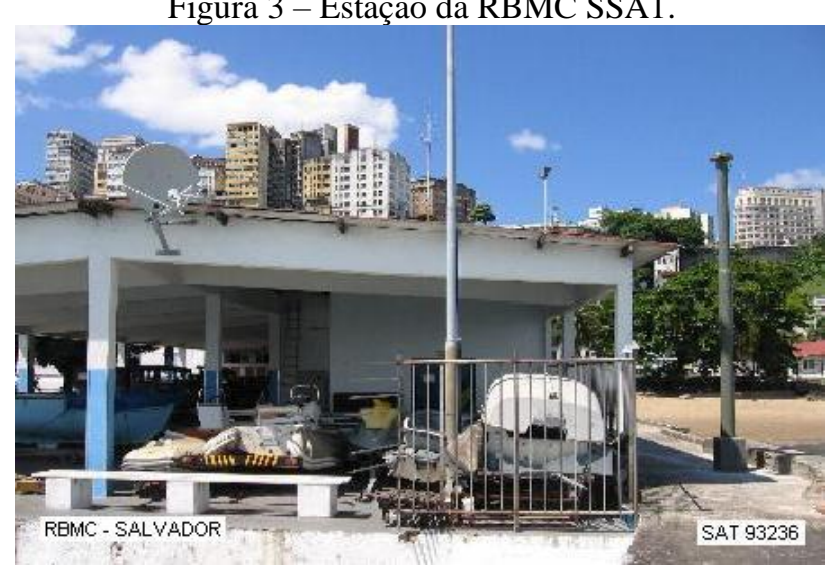

Fonte: IBGE (2020).

Para Dalazoana (2005), as aplicações dos dados GNSS devem-se a determinação e o monitoramento temporal da posição geocêntrica do marégrafo. Com a determinação da posição do marégrafo, o nível médio do mar (NMM) também pode ser definido num sistema geocêntrico (SGR). Ainda segundo a autora, a posição 
geocêntrica do marégrafo também é necessária para que o nível do mar observado pelo marégrafo possa ser definido no mesmo SGR utilizado pela altimetria por satélite. Esse monitoramento temporal da posição geocêntrica do marégrafo auxilia na discriminação de movimentos verticais locais e com isso na estimativa de variações absolutas do NMM. A situação ideal seria a estação GNSS acoplada diretamente na estação maregráfica, não sendo possível devido aos requisitos de instalação da mesma.

Contudo, dados de nivelamento geométrico em diferentes épocas foram utilizados. Esse tipo de levantamento não dá para ser correlacionado com os demais sensores pela sua periodicidade, mas é possível fazer uma análise do comportamento estrutural entre as estações GNSS e maregráfica.

\subsection{Metodologia}

A metodologia utilizada consistiu no tratamento dos dados extraídos da EMSAL, verificando o comportamento da série e corrigindo suas inconsistências, analisando sua memória ao longo do tempo e correlacionando com outras séries advindas das redes ativas e passivas do IBGE.

As inconsistências que podem ser detectadas numa análise inicial são basicamente três: ausência de dados, a existência de "gaps" e a existência de "outliers".

Os "outliers" referem-se a picos de variação no valor da altura de maré que exceda a tolerância préestabelecida entre um registro e outro, comum em sensores digitais ocasionados por algum tipo de interferência, mas que logo em seguida retorna à normalidade da curva registrada anteriormente.

Sua correção é feita com uma média simples das diferenças dos níveis de água registrados imediatamente antes e depois do evento.

As ocorrências registradas como "gaps" são picos de variação que excedem a mesma tolerância préestabelecida, mas que não voltam aos patamares registrados anteriormente, criando uma espécie de degrau na série. Embora o procedimento matemático seja simples, a construção da rotina de correção exige um pouco mais de complexidade no seu tratamento. São analisadas as 24 diferenças de fase anteriores e posteriores ao evento e gerado uma média dessa diferença. Como o "encoder" tem uma taxa de coleta de $5 \mathrm{~min}$, significa que essas médias são obtidas com base em 4 horas de observação, 2 horas antes e 2 horas depois.

O preenchimento para ausência de informações é idêntico ao procedimento aplicado na correção de "gaps", sendo a média encontrada das diferenças anterior e posterior aplicada a todo o período ausente.

Uma vez realizada as devidas correções das inconsistências conforme fluxograma da Figura 4, a série bruta vai dar origem a série controlada, trazendo-a para a mesma referência ou preenchendo os períodos ausentes com informações do encoder e/ou SLPR2, sem que haja perda na continuidade dos dados.

Figura 4 - Fluxograma dos processos de correção.

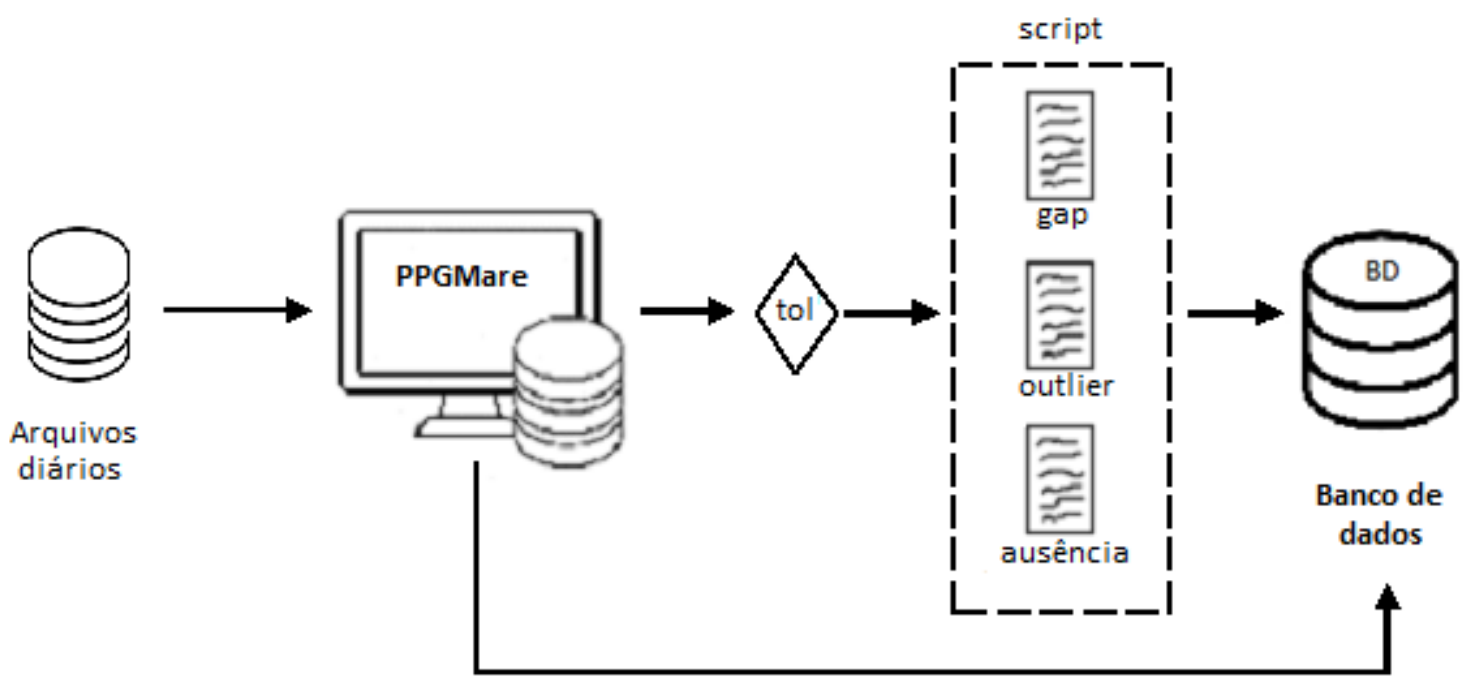

Fonte: Os autores (2021). 
Para tal, foi desenvolvido um sistema computacional na plataforma Delphi para as atividades de cálculos e correções, denominado PPGMare (RIBAS JUNIOR et al., 2019), onde a partir da inserção dos dados brutos diários de observação do nível do mar e dos processamentos semanais do SIRGASCON, é possível fazer uma análise inicial e detecção automática de possíveis inconsistências na inserção desses dados, correção monitorada dessas inconsistências, análise temporal (gráfica e descritiva) das séries GNSS e maregráfica, partição da série em dados diários, geração de médias diárias, preparação dos dados de correlação, entre outros.

Uma vez corrigida as inconsistências da série maregráfica, foi possível fazer o cálculo dos valores médios diários, tanto da série bruta quanto da série controlada, convertendo-as de contínua para uma série discreta de $N$ pontos. Em outras palavras, é gerado uma média aritmética simples, sem se preocupar com cálculos mais rigorosos para isso, como o filtro sugerido por Pugh (1996). Neste, as componentes diurnas e semi diurnas são removidas e um filtro de 119 pontos, centrado ao meio dia e com comprimento de cinco dias, é aplicado para remover a energia de alta frequência restante, sendo os valores mensais obtidos pela média simples dos valores diários (CALDWELL, 2002). A IOC (Intergovernmental Oceanographic Commission) indica que a escolha entre filtrar os dados para obter valores diários e então obter médias mensais e utilizar média simples para obter dados mensais, indica um procedimento estatístico mais rigoroso, não criticando o segundo (DALAZOANA, 2005).

Já para os cálculos de autocorrelação e correlação cruzada entre séries foram utilizados os métodos descritos no item 2, cujo o objetivo é não só avaliar a memória das séries, mas principalmente confirmar a existência de correlação entre a série maregráfica e a série GNSS. A escolha do método $\rho$ DCCA foi com base na literatura consultada que aponta este método como mais consistente. Kristoufek (2014) e Piao e Fu (2016), dizem que o coeficiente de correlação de Pearson é inadequado para séries temporais não estacionárias, já o $\rho D C C A$ é capaz de estimar o verdadeiro coeficiente de correlação entre as séries com precisão, independentemente da força de não-estacionariedade. Zhao et al. (2017) afirmam que o coeficiente de correlação cruzada DCCA apresenta um desempenho mais robusto para séries temporais não estacionárias e leva em consideração na modelagem detalhes sobre as forças de acoplamento em várias escalas de tempo. Para séries temporais contaminadas por tendências externas, o coeficiente de correlação cruzada DCCA é capaz de medir as correlações cruzadas intrínsecas em várias escalas de tempo (WANG et al., 2013; SILVA FILHO, 2014). Zebende (2011), aponta que o coeficiente de Pearson não é robusto e pode ser enganador se os outliers estiverem presentes porque os registros do mundo real são caracterizados por um alto nível de heterogeneidade.

\section{RESULTADOS E DISCUSSÕES}

Ao analisar a Figura 5, das médias diárias da série bruta, percebe-se que o início desta série é marcado por variações maiores, alertando que esse período merecia uma atenção maior na sua análise.

De fato, 2009 e 2010 foram os anos com maior quantidade de inconsistências. Embora haja o registro, os dados não são consistentes e apresentam várias falhas, com momentos de oscilações não uniformes e até mesmo períodos de estagnação.

É importante mencionar que não foi possível identificar uma causa para as inconsistências ocorridas no ano de 2009. Entretanto, as inconsistências de 2010 ficaram por conta dos 3 últimos meses, ocasionada pela quebra do cabo de aço do sistema boia versus contrapeso que gerou período desconexo e consequente gap do encoder, assim como períodos ausentes de dados para ambos os sensores, oriundos de problemas com a bateria que alimenta o datalogger. 
Figura 5 - Valores médios diários do nível do mar na EMSAL.

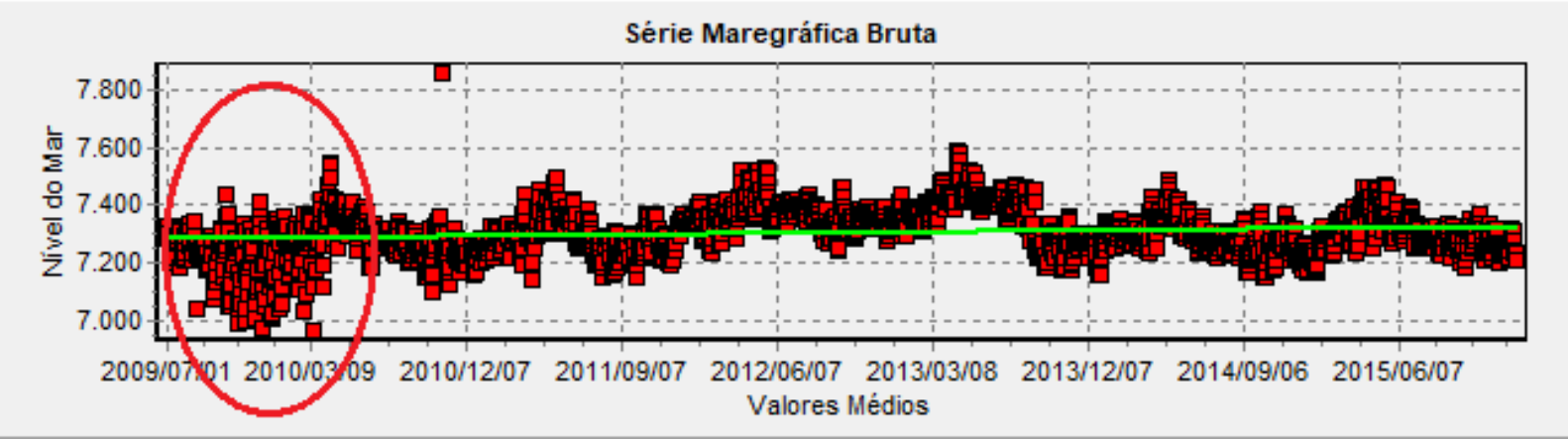

Fonte: PPGMare (RIBAS JUNIOR et al., 2019).

A partir de abril de 2011 os dados passaram a ter um comportamento mais estável, refletidos nos resultados da Tabela 1. Entretanto, o ano de 2012 foi responsável por uma grande quantidade de dados duplicados que foram suprimidos.

Tabela 1 - Porcentagem anual do tratamento dos dados da EMSAL.

\begin{tabular}{c|c|c|c}
\hline Ano & Dados originais $(\boldsymbol{\%})$ & $\begin{array}{c}\text { Dados corrigidos pelo } \\
\text { encoder }(\boldsymbol{\%})\end{array}$ & $\begin{array}{c}\text { Dados complementados } \\
\text { pelo SLPR (\%) }\end{array}$ \\
\hline 2009 & 83,88 & 16,08 & 0,04 \\
2010 & 84,99 & 11,09 & 3,92 \\
2011 & 89,96 & 3,07 & 6,97 \\
2012 & 98,03 & 0,32 & 1,65 \\
2013 & 99,62 & 0,07 & 0,31 \\
2014 & 99,45 & 0 & 0,55 \\
2015 & 100 & 0 & 0 \\
2009 a 2015 & 94,46 & 3,48 & 2,06 \\
\hline
\end{tabular}

Fonte: PPGMare (RIBAS JUNIOR et al., 2019).

Ao final de todo o processo de carga dos dados brutos, foram gerados 3.420 .000 registros de dados controlados referentes a 2375 dias de observação. De um modo geral, 94,46\% dos dados foram mantidos em seu valor original, 3,48\% precisaram ser corrigidos e 2,06\% foram preenchidos com dados do SLPR2.

Tabela 2 - Valores médios diários na EMSAL.

\begin{tabular}{c|c|c|c|c}
\hline Ano & $\begin{array}{c}\text { Valores médios } \\
\text { brutos }(\mathbf{m m})\end{array}$ & $\begin{array}{c}\text { Variação dos dados } \\
\text { brutos (mm/ano) }\end{array}$ & $\begin{array}{c}\text { Valores médios } \\
\text { controlado (mm) }\end{array}$ & $\begin{array}{c}\text { Variação dos dados } \\
\text { controlados (mm/ano) }\end{array}$ \\
\hline 2009 & 7224 & - & 7256 & - \\
2010 & 7276 & 52 & 7290 & 34 \\
2011 & 7291 & 15 & 7292 & 2 \\
2012 & 7364 & 73 & 7365 & 73 \\
2013 & 7357 & -7 & 7396 & 31 \\
2014 & 7288 & -69 & 7407 & 11 \\
2015 & 7301 & 13 & 7420 & 13 \\
2009 a 2015 & 7306 & - & 7354 & - \\
\hline
\end{tabular}

Fonte: PPGMare (RIBAS JUNIOR et al., 2019).

Na Tabela 2 são apresentados os valores médios diários, tanto ano a ano como para todo o período estudado, onde observa-se uma tendência de equiparação entre as diferenças adjacentes nos dados brutos com as mesmas diferenças para os dados controlados com o passar dos anos, sendo 2013 uma exceção nessa linha de tendência. Isso de fato só acontece porque a quantidade de correções na segunda metade do período foi praticamente nula ou acontecem de modo muito pontual. Entretanto, fazendo uma comparação descritiva desses valores, percebe-se que os dados controlados são mais estáveis (Figuras 6).

O comportamento com menor variação nas médias controladas se reflete nas demais medidas descritivas (assimetria, coeficiente de variação e curtose) (gráficos à direita) (Figura 6). 
Figura 6 - Descritiva dos valores médios diários brutos e controlados na EMSAL.
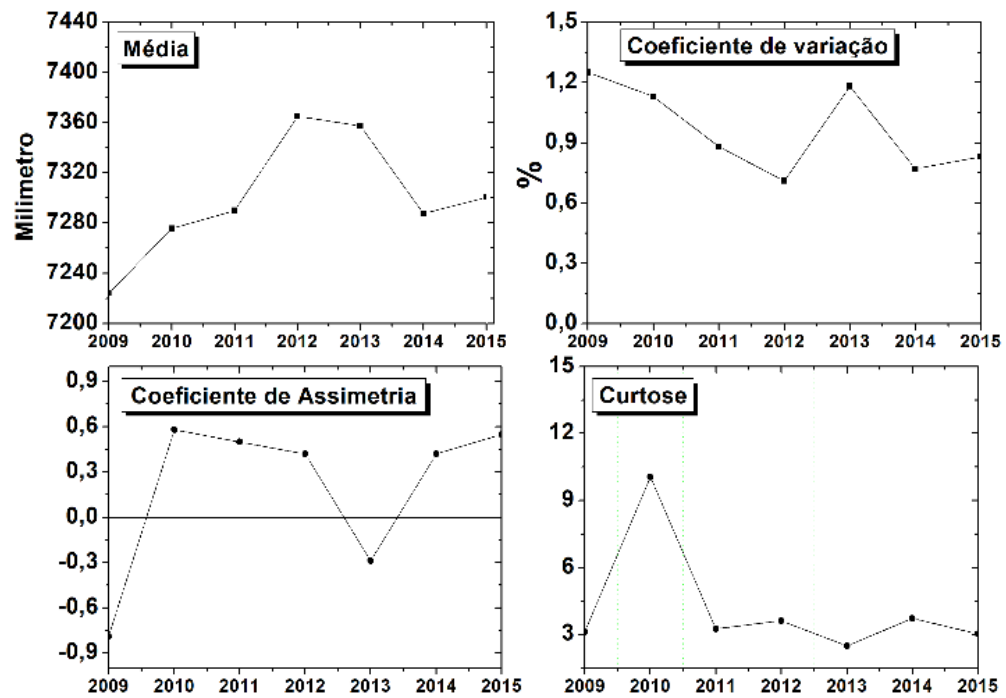

Ano
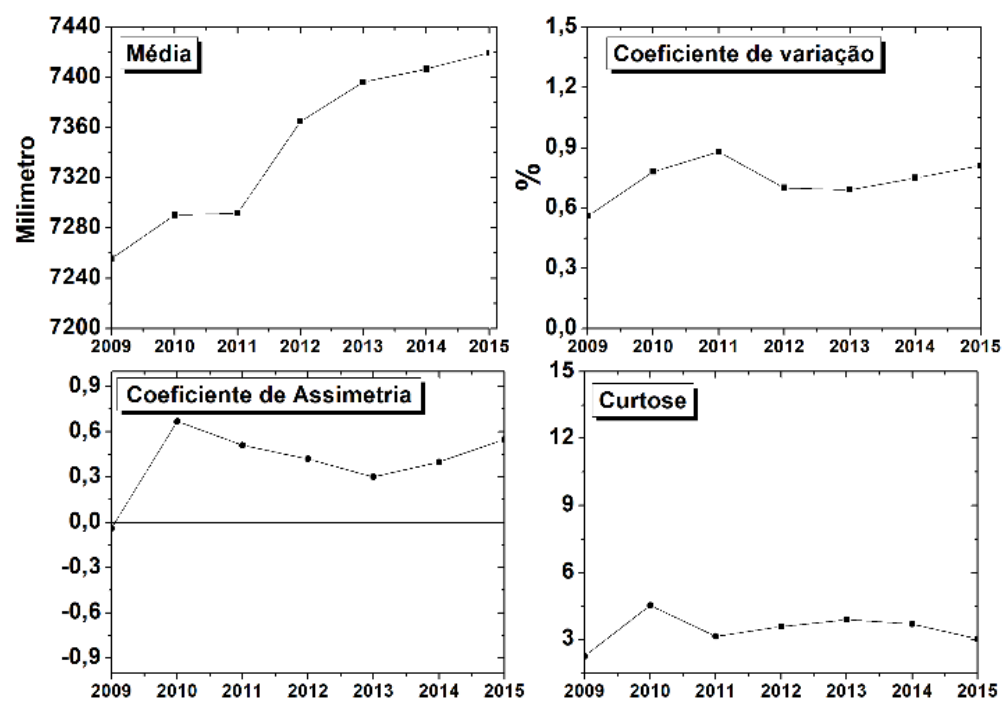

Ano

Fonte: Os autores (2021).

As discrepâncias entre os dados brutos e controlados também podem ser observadas na questão do incremento. Enquanto que os dados brutos resultaram numa variação altimétrica anual de $6,49 \mathrm{~mm}$, os dados controlados registraram quatro vezes mais esse valor que foi de $28,17 \mathrm{~mm} /$ ano (Figura 7).

De acordo com o IBGE (2016), também observado na Figura 7, percebe-se na estação de Salvador uma componente sazonal nas flutuações das séries. Ainda segundo o instituto, as variações do NMM nas estações da RMPG (Rede Maregráfica Permanente para a Geodésia) estão de acordo com as observações obtidas dos satélites altimétricos (CNES, 2016), que apontam para uma variação global de 3,4 mm/ano. Entretanto, não se pode comparar os valores encontrados pelo IBGE com os valores apresentados nesta pesquisa, uma vez que o instituto se utilizou de todo o período de atividade da EMSAL. Outra questão relevante é que a RMPG trabalha com uma tolerância de $20 \mathrm{~cm}$ na inconsistência dos dados, o que passaria despercebido o salto ocorrido em setembro de 2013 que fora na casa dos $12 \mathrm{~cm}$. Se o mesmo fosse ignorado, este incremento seria de apenas 2,98 $\mathrm{mm} /$ ano para os dados controlados. 
Figura 7 - Valores médios diários na EMSAL.

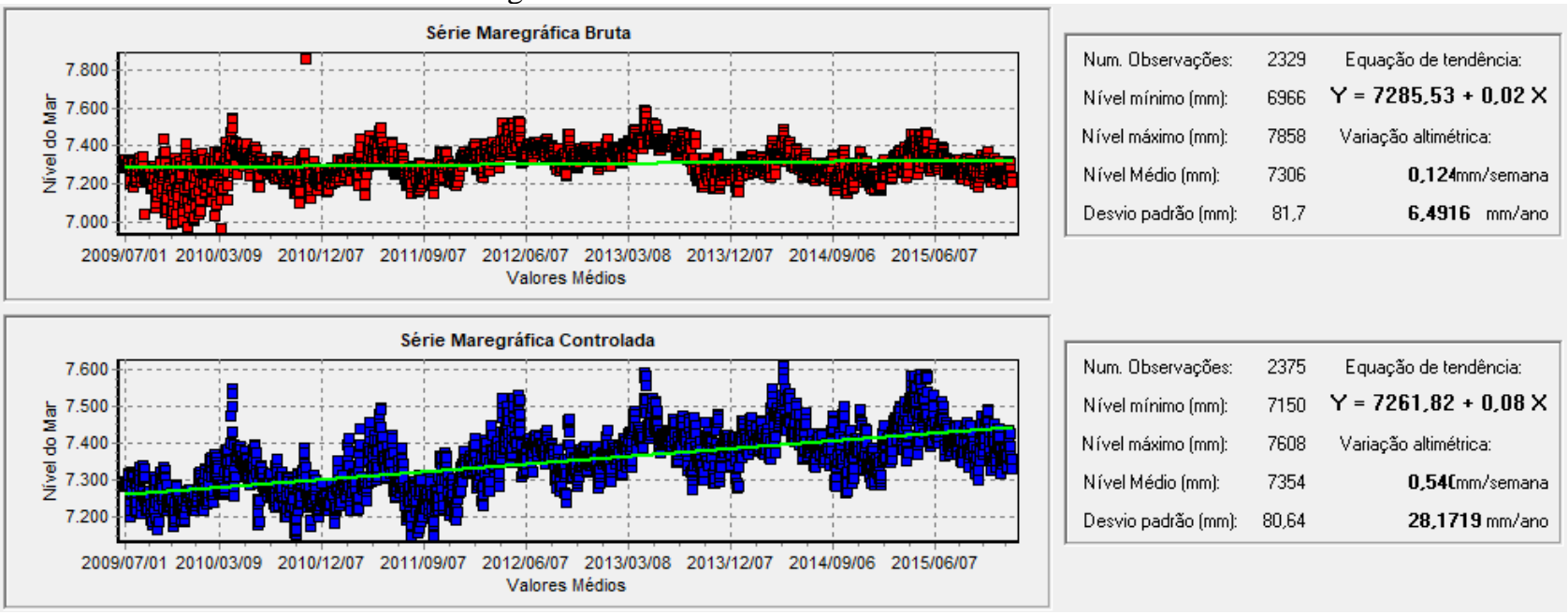

Fonte: PPGMare (RIBAS JUNIOR et al., 2019).

Essa taxa de variação relativamente alta é percebida pela sociedade com cenas cada vez mais frequentes do avanço do mar nas orlas urbanas, como o avanço do mar recentemente presenciado na região sul da Ilha de Itaparica (WENDEL, 2018; G1 Bahia, 2019) e outros tantos exemplos ao longo de toda a costa brasileira. Dalazoana (2005), com base em afirmações de outros autores e relatados pelo IPCC, chega a mencionar uma possível aceleração na elevação do NMM.

\subsection{Autocorrelação e Correlação Cruzada}

Ao modelar uma série temporal, o interesse pode estar em investigar o mecanismo gerador da série, fazer previsões de movimentos futuros a curto, médio e longo prazo, descrever o comportamento da série, procurar periodicidades relevantes (MORETIN; TOLOI, 2004).

Para análise das previsões futuras utilizou-se o método DFA no sentido de analisar a autocorrelação ou memória da série. A Tabela 3 mostra os expoentes obtidos por meio do DFA para cada ano da série de valores médios diários, assim como seu valor para todo o período com seus respectivos erros padrões.

Tabela 3 - DFA nas séries temporais dos níveis de maré média diária da EMSAL.

\begin{tabular}{c|c|c}
\hline Ano & Alfa (erro) dos dados brutos & Alfa (erro) dos dados controlados \\
\hline 2009 & $0,73 \pm 0,04$ & $0,99 \pm 0,03$ \\
2010 & $0,74 \pm 0,02$ & $0,90 \pm 0,02$ \\
2011 & $0,99 \pm 0,01$ & $0,97 \pm 0,02$ \\
2012 & $0,90 \pm 0,02$ & $0,90 \pm 0,02$ \\
2013 & $0,94 \pm 0,03$ & $0,79 \pm 0,03$ \\
2014 & $0,84 \pm 0,03$ & $0,84 \pm 0,03$ \\
2015 & $0,99 \pm 0,02$ & $0,99 \pm 0,01$ \\
2009 a 2015 & $1,09 \pm 0,001$ & $1,07 \pm 0,001$ \\
\hline
\end{tabular}

Fonte: Os autores (2021).

Observa-se que a modelagem do DFA nos níveis médios diários, tanto dos dados brutos quanto dos dados controlados, apresenta comportamento persistente $(\alpha>0,50)$, assim como o cálculo do valor de $\alpha$ para todo o período em estudo. Significa dizer que, de acordo com as propriedades estatísticas do DFA, é possível afirmar que ambas as séries têm memória e, caso exista uma tendência de aumento ou redução no nível do mar, este comportamento tende a continuar ocorrendo a longo prazo ou a longo alcance, corroborando com as estimativas encontrados no relatório do IPCC (2013).

Entretanto, não é suficiente analisar simplesmente os dados de maré, uma vez que outros fatores podem estar interferindo e inserindo ruídos não oriundos da variação do nível do mar. A vantagem de se usar dados oriundos do sistema GNSS é a possibilidade de se obter variações altimétricas do terreno sem a interferência de componentes físicos. 
Com a finalidade de comprovar a correlação entre os dados GNSS e os dados de maré foi aplicado o método $\rho$ DCCA.

Figura $8-\rho D C C A$ entre SSA1 e EMSAL para os dados brutos e dados controlados

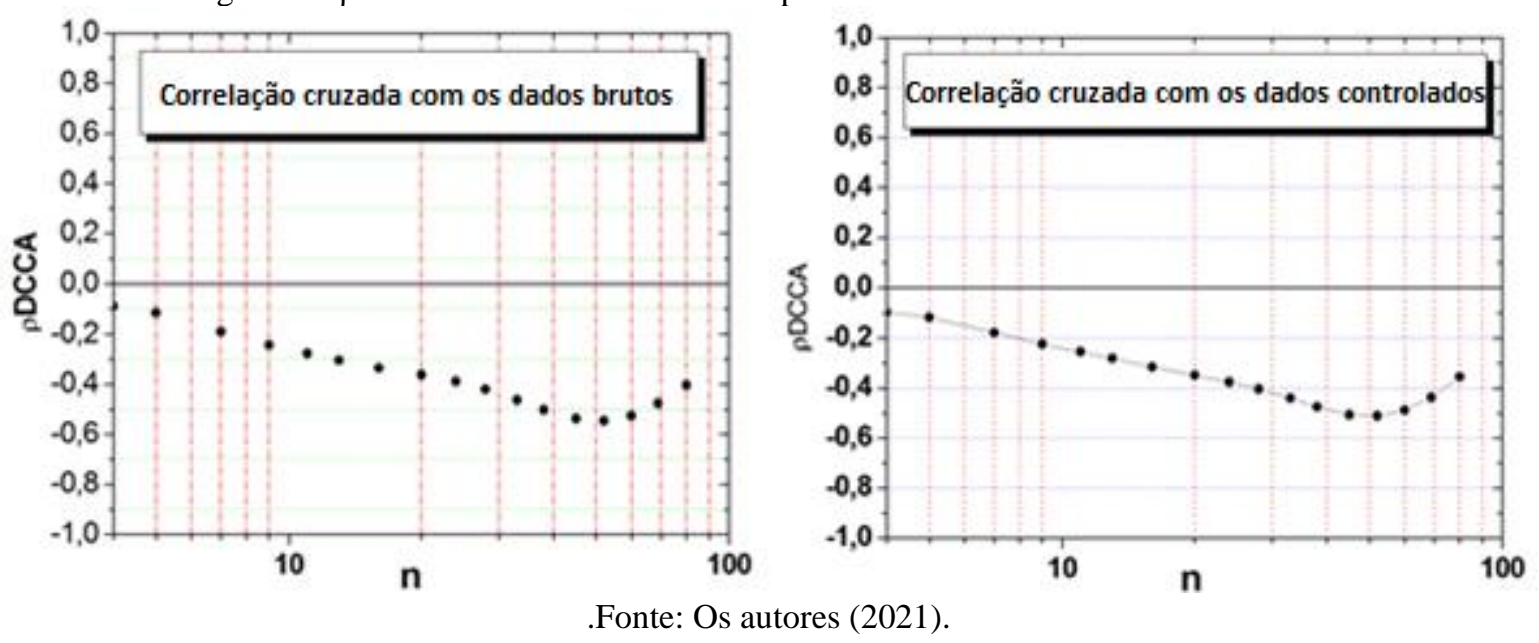

Ao se analisar os resultados apresentados na Figuras 8, percebe-se uma correlação inversa entre as duas séries nas diversas escalas de tamanho $n$ (semanas), tanto para o cruzamento da série GNSS com a série bruta quanto com a série controlada. Significa dizer que as variações apresentadas pela série GNSS interferem de maneira inversamente correlacionada na série maregráfica e que estatisticamente é indiferente se o dado foi corrigido ou não. Segundo Zebende, Brito e Castro (2020), o $\rho$ DCCA é um coeficiente capaz de mensurar correlação cruzada em séries que apresentam falhas ou interrupções sem perda na qualidade dos resultados obtidos, como é o caso das séries temporais contempladas nesta pesquisa.

\subsection{Série Maregráfica (Linhas de Tendência)}

Uma rotina para o cálculo da variação GNSS foi desenvolvido no PPGMare (RIBAS JUNIOR et al., 2019), onde dos 338 registros encontrou-se um erro médio de $3,38 \mathrm{~mm}$, um desvio padrão de $6,97 \mathrm{~mm}$ e a equação de regressão linear apresentada na Eq. (6), sendo $t$ representado em semanas (Figura 9).

$$
Y=31,55-0,02 t
$$

Esses registros já são os próprios resultados do SIRGASCON utilizados como insumo e visualizados no canto esquerdo da Figura 9, sendo assim dispostos: semana GNSS, data inicial da semana, data final da semana e o erro na coordenada vertical da semana em questão. Esse erro entende-se por ser a diferença entre o processamento corrente e o processamento que determinou as coordenadas oficiais da estação.

Os resultados mostram uma variação que tende a decrescer $0,0205 \mathrm{~mm}$ por semana, ou seja, uma variação de aproximadamente $1,07 \mathrm{~mm}$ / ano apenas na componente altimétrica do sistema GNSS que precisa ser repassado para os valores médios de maré, dando origem a série corrigida. 
Figura 9 - Análise estatística da série GNSS em SSA1.

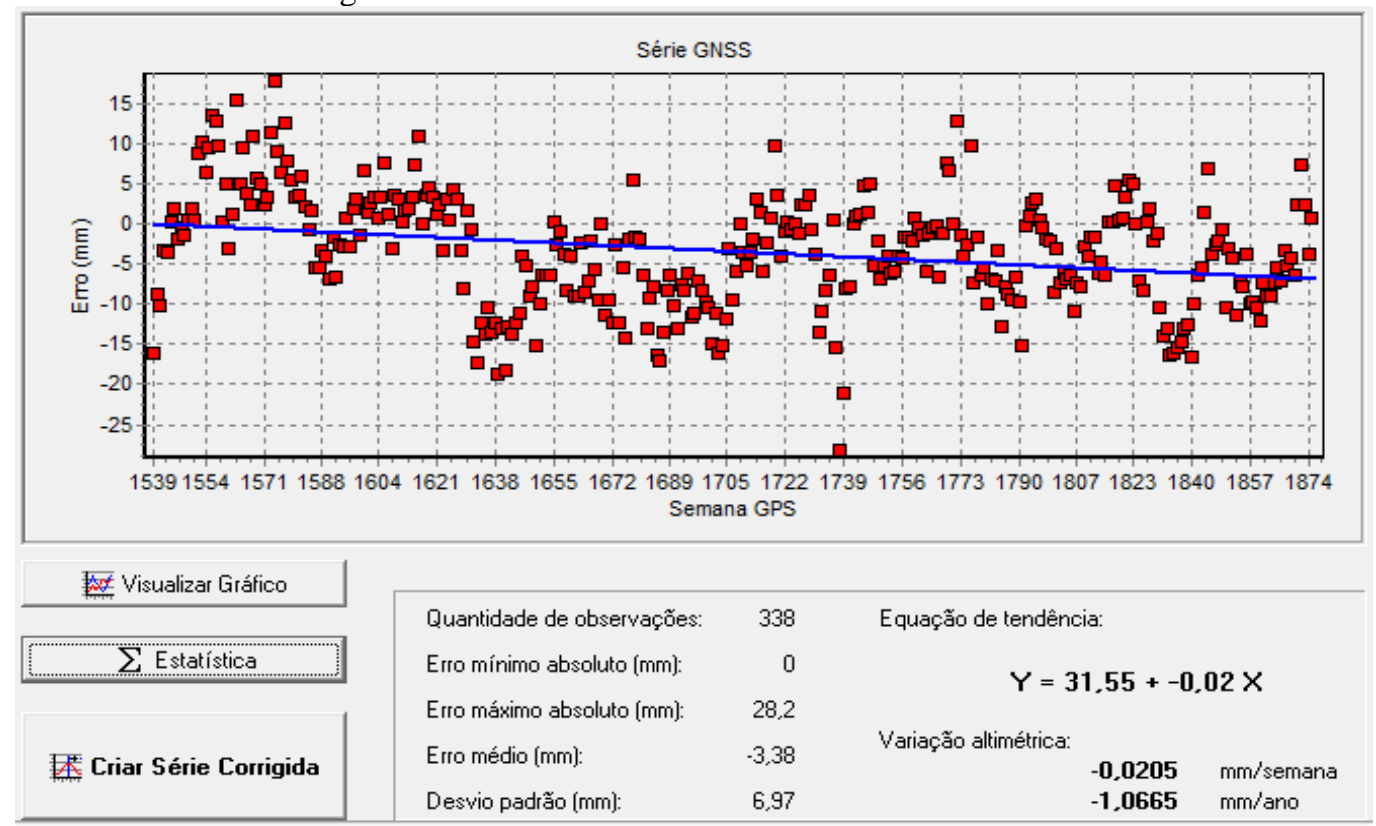

Fonte: PPGMare (RIBAS JUNIOR et al., 2019).

Evidente que outros fatores podem influenciar nos valores do NMM, tais como: temperatura, precipitação, correntes oceânicas, etc. Entretanto, buscou-se aqui identificar e isolar forças físicas de origem não oceânica. Sendo assim, outra questão que precisa ser levada em consideração é o soerguimento ou rebaixamento na faixa dos 150 metros que separam a estação GNSS da estação maregráfica. Para tal, buscouse separar este espaço em 3 trechos, sendo eles do continente para o quebra-mar (3652M - 3671B), do quebramar para o píer (3671B - 3671A) e do píer para o sensor radar (3671 A - 3671G), conforme visualizados na Figura 10 e materializados em chapas metálicas como referências de nível (RRNN). Vale ressaltar que o estudo baseou-se nos desníveis entre as RRNN obtidos por nivelamento geométrico de alta precisão, embora a função destas seja o fornecimento de altitudes calculadas e ajustadas a partir desses desníveis.

Figura 10 - Desnível entre SSA1 e EMSAL.

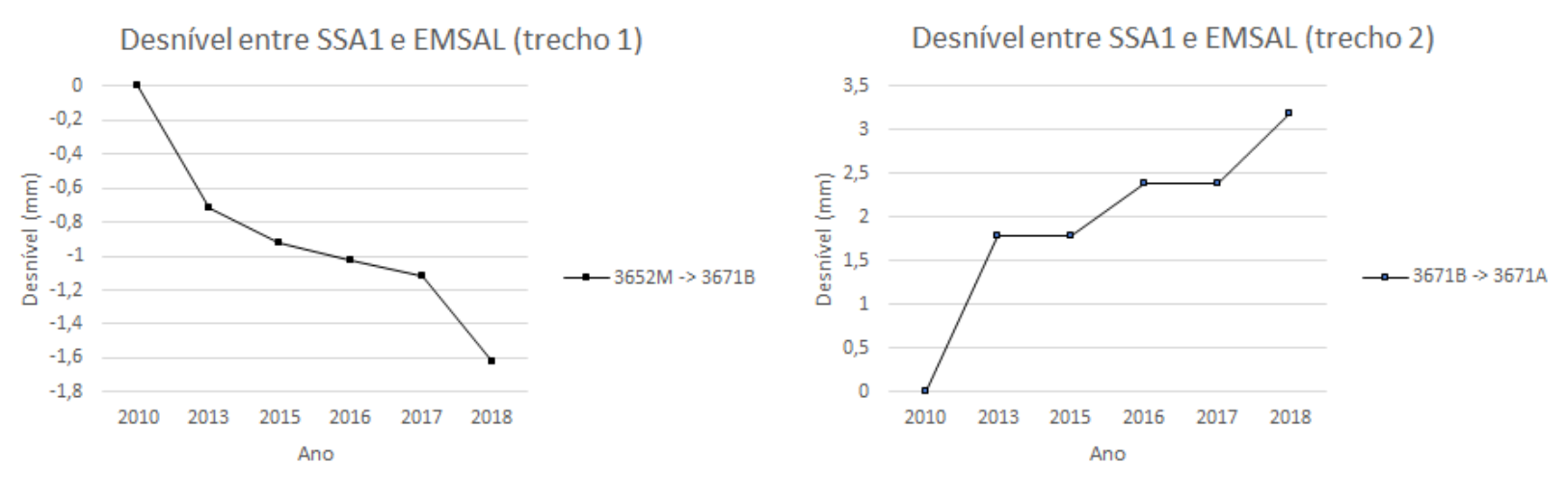

Desnível entre SSA1 e EMSAL (trecho 3)

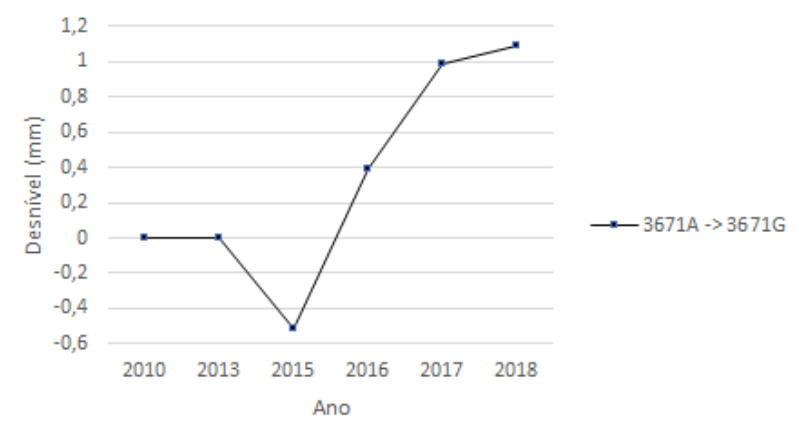

Fonte: Os autores (2021). 
Num período de 8 anos, o trecho 1 apresentou uma tendência de afastamento negativo do continente para o quebra-mar (-1,6 mm), o trecho 2 um afastamento positivo do quebra-mar para o píer $(3,2 \mathrm{~mm})$ e o trecho 3 um afastamento positivo do píer para o sensor $(1,1 \mathrm{~mm})$. Entretanto, considerando o universo temporal desta pesquisa (2009 a 2015), esses números são reduzidos para $-0,9,1,75$ e $-0,5 \mathrm{~mm}$, respectivamente. Analisando todo o conjunto, percebemos que esses trechos se compensam e contribuem com uma movimentação vertical de $0,35 \mathrm{~mm}$ para todo o período ou menos que $0,1 \mathrm{~mm}$ em média por ano (Figura 10).

Embora os números apresentem uma certa estabilidade em virtude das compensações entre os trechos, estudar o comportamento estrutural do local é fundamental na análise conjunta com os dados oriundos do sistema GNSS.

A modelagem executada nesta pesquisa constatou que no período estudado a soma das variações provenientes do sistema GNSS e do nivelamento geométrico entre os sensores pouco contribuíram no resultado final do NMM, visto a discrepância entre os valores encontrados. No entanto, $1 \mathrm{~mm}$ de variação anual foram atribuídas a estas forças de origem não oceânica e precisam ser levadas em consideração.

\section{CONSIDERAÇÕES FINAIS}

A presente pesquisa teve como objetivo avaliar o comportamento temporal do nível médio do mar da estação meregráfica de Salvador no periodo de 2009 a 2015 e também, buscando detectar e quantificar movimentos verticais de origem não oceânica que tendem a mascarar a qualidade desses dados. As rotinas computacionais criadas para detecção e correção semi-automática das inconsistências nas séries maregráficas atenderam satisfatoriamente ao que fora proposto, refletido nos resultados apresentados na comparação descritiva das séries brutas e controladas. Entretanto, esta última apresentou uma elevação 4 vezes mais que a série bruta e até 8 vezes mais que a média mundial que atualmente está em torno de $3,4 \mathrm{~mm}$. Vale ressaltar que os valores apresentados traduzem apenas uma amostra e que para uma análise mais precisa do aumento do nível do mar necessitaria de uma série três vezes maior que a utilizada nesta pesquisa. Além disso, outros fatores precisariam ser levados em consideração na modelagem do nível do mar, tais como: precipitação, correntes oceânicas, temperatura, etc. Adicionalmente, o fato do período em estudo ser de aproximação lunar, já se espera um aumento do nível médio do mar ocasionado pela força gravitacional entre a Terra e a Lua.

Os resultados obtidos pela modelagem do DFA, considerando suas propriedades, vêm corroborar com as afirmações de Camargo e Harari (2015) em que o movimento oscilatório do nível do mar merece destaque por sua periodicidade absolutamente regular, mostrando um coeficiente persistente $(\alpha>0,50)$, evidenciando que a série tem memória e que o comportamento de elevação no nível do mar tende a continuar ocorrendo a longo prazo.

Os resultados apresentados pelo $\rho$ DCCA identificaram uma correlação negativa entre a série oriunda dos dados GNSS com aquela advinda da variação do nível do mar para todas as escalas de tempo de tamanho $n$ (semanas), reforçando o princípio de que os valores de variação vertical, encontrados na série GNSS, precisam ser incorporados à série maregráfica com o objetivo fim de isolar forças verticais que não sejam de origem oceânica.

O fato é que o tema precisa ser tratado com extrema relevância e rigor científico, independentemente do caminho seguido. Do ponto de vista geodésico, a identificação de autocorrelação (memória de longo alcance) a partir do método DFA e uma tendência de crescimento demonstrada com o modelo de regressão linear simples, levanta o questionamento se ainda vale a pena manter um referencial altimétrico oficial de um país como estático e determinado há mais de 50 anos atrás. Do ponto de vista socioeconômico, é necessário que as autoridades monitorem essa questão com celeridade e eficiência na tomada de decisões e ações que protejam nossa costa.

O mapeamento de riscos e vulnerabilidades, por exemplo, precisa ser urgentemente inserido nos planejamentos e orçamentos da União, Estados e Municípios. Mais do que isso, é preciso aprofundar o conhecimento científico, aprimorar a rede de coleta de dados e enxergar que os ecossistemas costeiros, devido à função de proteção natural da linha de costa, são os principais agentes para adaptação às mudanças climáticas e aos riscos costeiros que já estão em curso. $\mathrm{O}$ avanço acelerado do nível do mar é uma preocupação mundial e poucas iniciativas existem no universo brasileiro que tratam do tema. 


\section{Agradecimentos}

Os autores agradecem ao Programa de Pós-graduação em Modelagem em Ciências da Terra e do Ambiente (PPGM-UEFS) pelo apoio e ao Instituto Brasileiro de Geografia e Estatística (IBGE) pela disponibilização dos dados utilizados nesta pesquisa.

\section{Contribuição dos Autores}

Este artigo foi desenvolvido a partir da pesquisa realizada no mestrado acadêmico do autor principal, sendo a contribuição de cada um dos autores da seguinte forma: Nilton de Souza Ribas Junior desenvolvimento dos algoritmos de correção e análise, processamento dos dados, conceptualização, redação, revisão e edição final; Carlos Antônio de Souza Teles Santos - orientação; Gilney Figueira Zebende desenvolvimento de algoritmos de processamento; Aló́sio Machado da Silva Filho - processamento dos dados, revisão e edição final.

\section{Conflitos de interesse}

Os autores declaram que não há conflito de interesses.

\section{Referências}

ALBARICI, F. L.; GUIMARÃES, G. DO N.; TRABANCO, J. L. A.; SANTOS, M. Modelagem dos Efeitos Geodinâmicos que afetam as Medições Maregráficas e GNSS. Revista Brasileira de Cartografia, v. 71, n. 1, p. 75-98, Mar 2019. DOI. 10.14393/rbcv71n1-46124.

G1 Bahia. Avanço da maré preocupa moradores e causa prejuízo em praia na Ilha de Itaparica. Disponível em: <https://g1.globo.com/ba/bahia/noticia/2019/08/05/avanco-da-mare-preocupamoradores-e-causa-prejuizo-em-praia-na-ilha-de-itaparica.ghtml>. Acesso em: 5 jun. 2020.

CALDWELL, P. IOC/GLOSS Technical Visit to the Brazilian Naval Directorate of Hydrography and Navigation. Visita realizada de 2 a 6 de setembro de 2002. Disponível em: <http://www.mares.io.usp.br/aagn/61/cald/cald.html>. Acesso em: 28 out. 2020.

CAMARGO, R.; HARARI, J. Marés. In: CASTELLO, J. P.; KRUG, L. C. (Orgs). Introdução as Ciências do Mar. Pelotas: Ed. Textos, p. 226-255, 2015.

CARRÈRE, L.; LYARD, F.; CANCET, M.; GUILLOT, A.; PICOT, N. FES 2014, a new tidal modelValidation results and perspectives for improvements. In: PROCEEDINGS OF THE ESA LIVING PLANET SYMPOSIUM 2016, Prague, Czech Republic, 9-13 May 2016.

CENTRE NATIONAL D'ÉTUDES SPATIALES (CNES). AVISO: Archivage, Validation et Interprétation dês données dês Satellites Océanographiques, 2016. Disponível em: <https://www.aviso.altimetry.fr/ >. Acesso em: 4 mai. 2020.

CORDEIRO, G. M.; PAULA, G. A. Modelos de Regressão para Análise de Dados Univariados. Rio de Janeiro: IMPA, 1989. 353 p.

CORREA, S. M. B. B. Probabilidade e Estatística, 2a . edição. Belo Horizonte: PUC Minas, 2003.

COSTA, S. M. A.; SILVA, A. L.; LIMA, M. A. A.; MOURA JUNIOR, N. J. Centro de Análise Sirgas - IBGE: novas estratégias de processamento e combinação, e a influência da mudança do referencial global nos resultados. Boletim de Ciências Geodésicas., Curitiba, v.18, n.1, p. 63-85, Mar 2012. DOI. 10.1590/s1982-21702012000100004.

DALAZOANA, R. Estudos dirigidos à análise temporal do Datum Vertical Brasileiro. 2005. 188f. Tese (Doutorado em Ciências Geodésicas) - Programa de Pós-Graduação em Ciências Geodésicas, Universidade Federal do Paraná, Curitiba, 2005. 
FOLGER, T. E se o mar subir? Miami vai virar uma ilha. As Maldivas vão sumir. Revista National Geographic. São Paulo: Ed. Abril, 2013, Ano 14. No 162.

GUIMARÃES, P. R. B. Métodos Quantitativos Estatísticos. 1ª edição. Curitiba: IESDE Brasil S.A., 2008.

HATJE, V.; ANDRADE, J. B. Baía de Todos os Santos: Aspectos Oceanográficos. Salvador: EDUFBA, 2009.

INTERNATIONAL ASSOCIATION OF GEODESY (IAG). Resolution no 1. Prague, Jul. 2015. Disponível em: < https://iag.dgfi.tum.de/fileadmin/IAG-docs/IAG_Resolutions_2015.pdf>. Acesso em: 06 jun. 2019.

INSTITUTO BRASILEIRO DE GEOGRAFIA E ESTATÍSTICA (IBGE). Análise do Nível Médio do Mar nas Estações da Rede Maregráfica Permanente para a Geodésia - RMPG 2001/2015, 2016. Disponível

em:

<ftp://geoftp.ibge.gov.br/informacoes_sobre_posicionamento_geodesico/rmpg/relatorio/relatorio_RMPG _2001_2015_GRRV.pdf>. Acesso em:13 mai. 2019.

INSTITUTO BRASILEIRO DE GEOGRAFIA E ESTATÍSTICA (IBGE). Especificações e Normas para Levantamentos Geodésicos associados ao Sistema Geodésico Brasileiro, 2017. Disponível em: <ftp://geoftp.ibge.gov.br/metodos_e_outros_documentos_de_referencia/normas/normas_levantamentos_ geodesicos.pdf>. Acesso em: 06 jun. 2019.

INSTITUTO BRASILEIRO DE GEOGRAFIA E ESTATÍSTICA (IBGE). Instruções técnicas para Controle Geodésico de Estações Maregráficas - CGEM e sua vinculação vertical ao Sistema Geodésico Brasileiro - SGB. Manuais Técnicos em Geociências, n. 11. 2010. Disponível em: <ftp://geoftp.ibge.gov.br/documentos/geodesia/pdf/mtg11.pdf>. Acesso em: 17 ago. 2014.

INSTITUTO BRASILEIRO DE GEOGRAFIA E ESTATÍSTICA (IBGE). Reajustamento da Rede Altimétrica com Números Geopotenciais, 2018. Disponível em: <ftp://geoftp.ibge.gov.br/informacoes_sobre_posicionamento_geodesico/rede_altimetrica/relatorio/relato rio_REALT_2018.pdf>. Acesso em: 06 jun. 2019.

INSTITUTO BRASILEIRO DE GEOGRAFIA E ESTATÍSTICA (IBGE). Relatório de Estação Geodésica. Disponível em: < http://www.bdg.ibge.gov.br/bdg/pdf/relatorio.asp?L1=93236 >. Acesso em: 04 jun. 2020.

INSTITUTO BRASILEIRO DE GEOGRAFIA E ESTATÍSTICA (IBGE). Relatório de Monitoramento da Variação do Nível Médio do Mar nas Estações da Rede Maregráfica Permanente para Geodésia 2001-2012, 2013. Disponível em: <ftp://geoftp.ibge.gov.br/RMPG/relatorio/relatorio_RMPG_2001_2013 _GRRV.pdf>. Acesso em: $12 \mathrm{dez} .2013$.

IHDE, J., SÁNCHEZ, L., BARZAGHI, R. et al. Definition and Proposed Realization of the International Height Reference System (IHRS). Surveys in Geophysics, v. 38, p. 549-570, Mai 2017. DOI. 10.1007/s10712-017-9409-3

INTERGOVERNMENTAL PANEL ON CLIMATE CHANGE (IPCC). Climate Change 2013: The Physical Science Basis. Contribution of Working Group I to the Fifth Assessment Report of the Intergovernmental Panel on Climate Change [STOCKER, T.F., D. QIN, G.-K. PLATTNER, M. TIGNOR, S.K. ALLEN, J. BOSCHUNG, A. NAUELS, Y. XIA, V. BEX AND P.M. MIDGLEY (eds.)]. Cambridge University Press, Cambridge, United Kingdom and New York, NY, USA, 1535 pp.

KRISTOUFEK, L. Measuring correlations between non-stationary series with DCCA coeficiente, Physica A: Statistical Mechanics and its Applications, v. 402, p. 291-298, Mai 2014. DOI. 10.1016/j.physa.2014.01.058.

MACHADO FILHO, A.; SILVA, M. da; ZEBENDE, G. F. Autocorrelation and crosscorrelation in time series of homicide and attempted homicide. Physica A: Statistical Mechanics and its Applications, v. 400, p. 1219, Apr 2014. DOI. 10.1016/j.physa.2014.01.015.

MARMER, H. A. Tidal Datum Planes. Special Publication No 135 Revised (1951) Edition, 1951.

NETO, G. M. S. Impactos do aumento do Nível Médio do Mar em algumas capitais do Nordeste 
Brasileiro, e suas consequências ambientais. 2009. 60f. Dissertação (Mestrado em Ciências Atmosféricas) - Programa de Pós-Graduação em Meteorologia, Universidade Federal de Campina Grande, Campina Grande, 2009.

PARRA, R. R. T.; LÓPEZ, J. C. G.; FRANCO, F. A. Variacion del nivel medio del mar en el Caribe Colombiano. Boletin Científico CIOH, n.24, p. 64-72, Dic. 2006. DOI. 10.26640/01200542.24.64_72.

PENG, C. K.; BULDYREV, S. V.; HAYLIN, S.; SIMONS, M.; STANLEY, H. E.; GOLDBERGER, A. L. Mosaic organization of dna nucleotides. Physical Review E, v. 49, n. 2, p. 1685-1689, Feb. 1994. DOI. 10.1103/PhysRevE.49.1685.

PIAO, L.; FU, Z. Quantifying distinct associations on different temporal scales: comparison of DCCA and Pearson methods. Scientific Reports, v. 6, n. 36759, Nov. 2016. DOI. 10.1038/srep36759.

PODOBNIK, B.; STANLEY, H. E. Detrended cross-correlation analysis: A new method for analyzing two nonstationary time series. Physical Review Letters, v. 100, p. 084102, Feb. 2008. DOI. 10.1103/PhysRevLett.100.084102.

PUGH, D. Tides, Surges and Mean Sea Level. New York: John Wiley and Sons, 1996.

RIBAS JUNIOR, N. S.; GUEDES, E. F.; SILVA FILHO, A. M. PPGMare (identifica, mensura e corrige série maregráfica de sensor vega e correlaciona-o com outras séries temporais). BR512019001100-7, 01 Jan. 2019, 25 Abr. 2019.

RIBEIRO, L. C. Contribuição para o estabelecimento do IHRF no Estado de São Paulo. 2019. $100 f$. Dissertação (Mestrado em Ciências Cartográficas) - Programa de Pós-Graduação em Ciências Cartográficas, Universidade Estadual Paulista "Júlio de Mesquita Filho", Presidente Prudente, 2019.

SAMPAIO, A. C. F.; MELO, A. A.; FARIA, A. P.; MENEZES, P. M. L. Oscilações do Nível do Mar no futuro e possíveis consequências no Brasil: Pequeno ensaio. Disponível em: <http://www.geocart.igeo.ufrj.br/pdf/trabalhos/2003/Oscilacao_Nivel_Mar_2003.pdf〉. Acesso em: 11 dez. 2019.

SÁNCHEZ, L.; SIDERIS, M. G. Vertical datum unification for the International Height Reference System (IHRS). Geophysical Journal International, v. 209, n. 2, p. 570-586, May 2017, DOI. 10.1093/gji/ggx025.

SANTOS, M. S. T.; AMARO, V. E.; FERREIRA, A. T. S.; BARBOSA, A. A.; FIGUEIREDO, M. C.; ARAÚJO, A. G. Metodologia para mapeamento de vulnerabilidade costeira à elevação do Nível Médio do Mar (NMM) em escala local. Boletim de Ciências Geodésicas, v. 21, n. 4, p. 691-705, Dez. 2015. DOI. 10.1590/S1982-21702015000400040.

SILVA FILHO, A. M. Autocorrelação e Correlação Cruzada: Teorias e Aplicações. 2014. 127f. Tese (Doutorado em Modelagem Computacional e Tecnologia Industrial) - Programa Pós-Graduação em Modelagem Computacional e Tecnologia Industrial, Faculdade de Tecnologia SENAI CIMATEC, Salvador, 2014.

TOCHO, C.N., ANTOKOLETZ, E.D., PIÑÓN, D.A. (2020) Towards the Realization of the International Height Reference Frame (IHRF) in Argentina. In: INTERNATIONAL ASSOCIATION OF GEODESY SYMPOSIA. Springer, Berlin, Heidelberg. DOI. 10.1007/1345_2020_93.

VEGA. Operating Instructions: Radar sensor for continuous level measurement of liquids VEGAPULS 62. Disponível em: <http://us.areva.com/home/liblocal/docs/Solutions/Product\%20Sales/VEGAPULS\%2062\%20Extended \%20Range\%20Manual\%20\%E2\%80\%93\%20Up\%20to\%20212\%20ft.pdf $>$. Acesso em: 04 mai. 2016.

ZEBENDE, G. F. Dcca cross-correlation coefficient: Quantifying level of cross-correlation. Physica A: Statistical Mechanics and its Applications, v. 390, n. 2, p. 614-618, Feb. 2011. DOI. 10.1016/j.physa.2010.10.022.

ZEBENDE, G. F.; SILVA, M. F.; MACHADO FILHO, A. DCCA cross-correlation coefficient differentiation: Theoretical and pratical approaches. Physica A: Statistical Mechanics and its Applications, v. 392, n. 8, 
p. 1756-1761, Apr. 2013. DOI. 10.1016/j.physa.2013.01.011.

ZEBENDE, G. F.; BRITO, A. A., CASTRO, A. P. DCCA cross-correlation analysis in time-series with removed parts. Physica A: Statistical Mechanics and its Applications, v. 545, May 2020. DOI. 10.1016/j.physa.2019.123472.

ZHAO, X.; SHANG, P.; HUANG, J. Several Fundamental properties of DCCA cross-correlation coefficient, World Scientific, v. 25, n. 02, Mar. 2017. DOI. 10.1142/S0218348X17500177.

WANG, G.; XIE, C.; CHENA, S.; YANG, J.; YANG, M. Random matrix theory analysis of cross-correlations in the US stock market: Evidence from Pearson's correlation coefficient and detrended cross-correlation coefficient. Physica A: Statistical Mechanics and its Applications, v. 392, n. 17, p. 3715-3730, Sep. 2013. DOI. 10.1016/j.physa.2013.04.027.

WENDEL, B. Mar destrói hotéis e restaurantes e ameaça residências na Ilha de Itaparica. Correio, Bahia, 14 set. 2018.

\section{Biografia do autor principal}

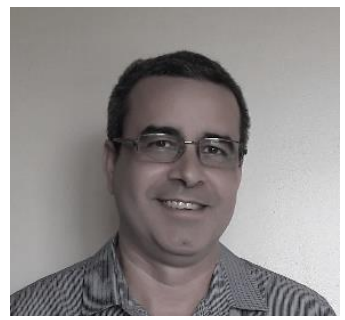

Nilton de Souza Ribas Júnior é natural de Recife/PE e nascido em 1975. Possui graduação em Engenharia Cartográfica pela Universidade Federal de Pernambuco (1999), mestrado em Ciências Ambientais pela Universidade Estadual de Feira de Santana (2019) e doutorando em Ciências Ambientais pela mesma instituição. Servidor Público Federal desde 2002, já executou diversos trabalhos de engenharia a nível local, regional e nacional. Atualmente, gerencia o Setor de Geodésia e Cartografia do IBGE no Estado da Bahia.

Esta obra está licenciado com uma Licença Creative Commons Atribuição 4.0 Internacional - CC BY. Esta licença permite que outros distribuam, remixem, adaptem e criem a partir do seu trabalho, mesmo para fins comerciais, desde que lhe atribuam o devido crédito pela criação original. 